\title{
Assessment of Water Resources Security in Semi Arid Area based on GIS-A Case Study in Naiman County, Inner Mongolia
}

\author{
Xiangqian Li, Zhijun Tong, Zhenhua Dong, Si Ha, Feng Zhang, Pengda Lin \\ School of Environment, Northeast Normal University, Institute of Natural Disaster Research, Northeast \\ Normal University, Changchun 130024, China

\section{基于 GIS 的半干旱区水资源安全评价研究 $=$ 一以内蒙古奈曼旗为例} \\ 李向前, 佟志军 ${ }^{*}$, 董振华, 哈斯, 张峰, 林鹏达 \\ 东北师范大学环境学院, 长春 130024 , 中国
}

\begin{abstract}
As basic production and living materials, water resources is essential for social-economic development, and is increasingly becoming the limiting factor of regional economic sustainable development. Naiman County is located in the south edge of Horqin sandy land, which faces great challenge of water resources shortage. In this paper, a case study on the security assessment of water resources is carried out in Naiman County, Inner Mongolia Autonomous Region by selecting 19 indexes to build up the index system of water resources security evaluation under the framework of Driver-Pressure-Status-Impact-Response model. Then with the help of GIS technology, the spatial characteristics of water resource safety is quantitative analyzed by calculating water resource safety index(WRSI). Results show that the water resource status is in bad
\end{abstract}

作者简介: 李向前 (1990-), 男, 天津市大 港人, 硕士研究生, 主要从事生态安全评价. E-mail:lixq264@nenu.edu.cn

*通讯作者: 佟志军 (1977-), 男, 辽宁兴城 人, 副教授, 硕士生导师, 主要从事 35 技术 及其在灾害风险评价与应急决策应用与开发 研究.E-mail:gis@nenu.edu.cn condition in Naiman as a whole, and the value of WRSI is significant differences within the region. Relatively low areas are mainly concentrated in the northwest, and relatively high areas are mainly concentrated in the southeast. In general, the safety level of water resources has the ascending trend from northwest to southeast.

Key words: water resources security; DPSIR; GIS; Naiman; spatial differentiation

\section{摘要}

水资源作为必不可缺的基本生产和生活资料, 正日益成为地区经济可持续发展的限制因子。 奈曼旗地处科尔汇沙地南缘, 水资源短缺是其 面临的重大挑战。本文通过 DPSIR (Driver-Pressure-State-Impact-Response) 模型构建水资源安全指标体系, 并借助 GIS 技术, 基于公里格网定量分析研究区水资源安 全的空间分异特征。结果显示: 奈曼旗水资源 安全整体水平较低, 水资源安全水平高的区域 主要集中在东南部, 水资源安全水平低的区域 主要集中在西北部, 总体上呈现出由西北向东 南递升的趋势。

关键词: 水资源安全; DPSIR; 格网; 奈曼旗; 空间分异 
Risk Analysis and Crisis Response in Big Data Era (RAC-16)

1. 引言

水, 作为一种重要的自然资源和经济资源, 既是生态环境的一个控制性因素, 又是国家综 合国力的有机组成部分 ${ }^{[1]}$ 。随着社会经济的快 速发展, 人类活动对水资源的大量消耗, 以及 对水质的严重污染, 水资源安全问题已经成为 全世界面临的重大挑战。我国水资源相对贫乏, 空间分布差异性大, 尤其是在西北部的干旱、 半干旱区, 水资源短缺和水质恶化引发了一系 列生态环境问题, 已经成为当地社会经济发展 的主要限制因子, 对水资源安全状况进行评价, 为干旱区经济发展中水资源合理配置提供科 学依据, 是我们当前积极、必要的工作。

国内外对水资源安全的研究多集中在 水资源优化管理 ${ }^{[2]}$ 、水资源合理配置 ${ }^{[3]}$ 、水 量及水质安全分析 ${ }^{[4-6]}$ 等方面, 而对水资源安 全综合评价的研究很少。水资源安全评价是 水资源安全研究的重要组成部分, 国内不少学 者运用人均水足迹标识法、WPI 指数法对水资 源安全进行评价。人均水足迹标识法和 WPI 指数法虽然快速, 但水资源安全状况是社会、 经济、自然诸多因素相互耦合的结果, 使用单 一指标无法反映这些要素相互影响、相互作用 难过的因果关系, 容易出现误差。在评价尺度 上, 目前水资源安全研究多以行政区作为研究 对象, 空间尺度较大, 虽然分析了水资源安全 的宏观空间特征, 然而现实表明水资源安全状 况在行政区内部仍存在差异, 以行政区划的平 均值来衡量整个评价单元的水资源安全状况, 具有一定的片面性, 使得行政区内部水资源安 全的空间分异特征难以体现。

本文尝试基于 DPSIR 概念模型, 选取我 国典型的半干旱农牧交错区一一奈曼旗作为 研究区域, 利用格网 GIS 技术, 通过对影响其 水资源安全的诸多要素进行空间格网化表达, 并确定科学、合理的水资源安全等级划分依据, 基于公里格网尺度对其水资源安全状况及其 空间格局变化规律进行定量评价, 既可以反映 评价体系中各要素相互作用的因果关系, 有助 于理解水资源安全的演化进程, 又分析了研究 区域内部水资源安全的空间分异特征, 同时从 水资源安全形成机理上揭示了奈曼旗水资源 安全存在空间差异的原因, 为水资源安全状况

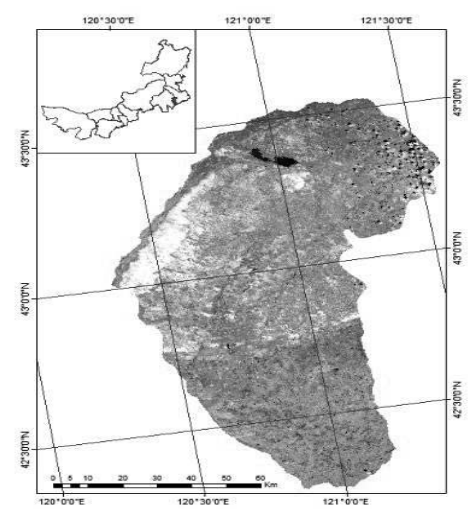

图 1 奈曼旗示意图

的诊断提供理论支撑和科学依据。

\section{2. 研究区概况}

奈曼旗位于内蒙古通辽市西南部, 区域地 理坐标为 $\mathrm{E} 120^{\circ} 19^{\prime} \sim 121^{\circ} 12^{\prime}, \mathrm{N} 41^{\circ} 60^{\prime}-46^{\circ} 78^{\prime}$, 全旗总面积 $8137.6 \mathrm{~km} 2$, 年降水量 343.3 $471.4 \mathrm{~mm}$, 多年平均降水量为 $366 \mathrm{~mm}$, 年蒸发 量 $1972.8 \sim 2081.8 \mathrm{~mm}$, 多年平均蒸发量 $1988 \mathrm{~mm}$ 。其境内共有大小 7 条河流, 地表水 总流量接近 5 亿立方米, 自然降水 3.2 3.4 亿 立方米, 但由于地表水源特点、人为水利工程 的失误和自然生态严重破坏等因素, 使 70\%以 上地表水成为客水流向下游, 仅有 $30 \%$ 存留在 境内。奈曼旗地处我国北方典型的半干旱农牧 交错区, 生态环境脆弱, 再加上长期以来当地 人口数量和耕地面积的持续增加, 使当地的自 然水循环系统平衡状态遭到严重破坏, 水资源 环境退化十分严重, 西湖水库、舍力虎水库均 已彻底干涸。水资源安全问题已经严重制约着 该地区社会经济的可持续发展, 也影响着周边 地区的生态安全。

\section{3. 研究方法与步骤}

\section{1. 理论框架}

水资源系统是自然、经济、社会诸多因素 相互影响相互作用的复杂系统, 在研究水资源 
Risk Analysis and Crisis Response in Big Data Era (RAC-16)

安全的形成机制时, 应该将这些因子作为综合 指标来考虑。联合国经济合作发展组织提出的 PSR 模型, 被国内学者广泛应用。但是 PSR 模型有一个明显缺陷: 人类活动对环境的影响 只能通过环境状态指标随时间的变化而间接 的反映出来 ${ }^{[7]}$ 。欧洲环境署基于 PSR 原理提出 的 DPSIR 模型有效地改善了这一缺陷。因此, 我们认为应用 DPSIR 模型来刻画水资源安全 的形成机制更为科学, 图 2 即描述了人类活动 与水资源环境之间相互作用的各因子之间的 因果关系。这条因果链表明社会、经济的发展、 人口的增长作为长期驱动力 (D) 作用于环境, 因而对环境产生压力（P），造成生态环境状 态 $(\mathrm{S})$ 的变化, 从而对生态环境造成各种影 响（I），这些影响促使人类对环境状态 (S) 的变化做出响应（R），响应（R）措施又作 用于社会、经济和人口所构成的复合系统或直 接作用于环境压力 $(\mathrm{P})$ 、状态 $(\mathrm{S})$ 和影响 $(\mathrm{I})$, 以使此反馈保持稳定与平衡 ${ }^{[8]}$ 。

\section{2. 水资源安全评价指标体系}

目前, 学术界尚未有统一认可的水资源安 全评价体系标准。在借鉴现有研究成果 ${ }^{[9-10]}$ 的 基础上, 我们基于 DPSIR 模型, 按照水资源 安全的内涵和要求, 根据科学性、全面性、可 靠性等原则, 并在参考相关专家意见的基础上

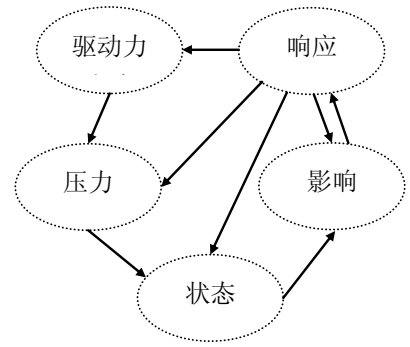

图 2 水资源安全形成机制

结合实地考察资料, 经 SPSS14.0 软件对初拟 指标进行篎选与可信度检验, 进而构建了适用 范围广、可行性强的水资源安全评价指标体系 （表 1)。其中, 指标权重值由熵权法计算。

\section{3. 水资源安全评价指标体系}

目前, 学术界尚未有统一认可的水资源安 全评价体系标准。在借鉴现有研究成果 ${ }^{[9-10]}$ 的 基础上, 我们基于 DPSIR 模型, 按照水资源 安全的内涵和要求, 根据科学性、全面性、可 靠性等原则, 并在参考相关专家意见的基础上 结合实地考察资料, 经 SPSS14.0 软件对初拟 指标进行篎选与可信度检验, 进而构建了适用 范围广、可行性强的水资源安全评价指标体系 （表 1)。其中, 指标权重值由熵权法计算。

表 1 水资源安全评价指标体系

\begin{tabular}{|c|c|c|c|}
\hline 目标层 & 准则层 & 指标层 & 权重 \\
\hline \multirow{19}{*}{$\begin{array}{l}\text { 水 } \\
\text { 资 } \\
\text { 源 } \\
\text { 安 } \\
\text { 全 } \\
\text { 综 } \\
\text { 合 } \\
\text { 评 } \\
\text { 价 }\end{array}$} & 驱动力系统 & 国内生产总值 GDP 年增长率 & 0.0703 \\
\hline & & 人口自然增长率 & 0.0591 \\
\hline & & 城镇化率 & 0.0434 \\
\hline & 压力系统 & 道路网密度 & 0.0225 \\
\hline & & 人均水资源量 & 0.0319 \\
\hline & & 人口密度 & 0.0850 \\
\hline & & 万元 GDP 产值用水量 & 0.0358 \\
\hline & & 化肥、农药使用量 & 0.0437 \\
\hline & 状态系统 & 河网密度 & 0.0774 \\
\hline & & 水域面积 & 0.0728 \\
\hline & & 年降水量距平百分率 & 0.0640 \\
\hline & & 年蒸发量距平百分率 & 0.0381 \\
\hline & 影响系统 & 湿润指数 & 0.0826 \\
\hline & & 生物丰度 & 0.0416 \\
\hline & & 林地覆盖率 & 0.0336 \\
\hline & & 草地覆盖率 & 0.0342 \\
\hline & 响应系统 & 生态与环保投入占 GDP 比重 & 0.0531 \\
\hline & & 有效灌溉面积 & 0.0683 \\
\hline & & 每万人拥有在校学生数 & 0.0426 \\
\hline
\end{tabular}


Risk Analysis and Crisis Response in Big Data Era (RAC-16)

\section{4. 水资源安全指数一WRSI 的构建}

依据水资源安全形成机制, 人类社会经济 活动对水资源环境的驱动力愈大, 其在水资源 环境中产生的压力就愈大, 从而对水资源安全 也更为不利, 即对水资源安全产生的不利影响 程度就愈大。由此可知, 驱动力、压力和影响 3 个准则层因子与区域水资源安全指数呈负相 关。如果一个区域原有的水资源环境状态较好, 那么该区域的水资源安全指数一般较高, 即状 态因子与水资源安全指数呈正相关。响应是人 类感知到生态环境恶化后所做出的正向修复 和补救保护措施 ${ }^{[11]}$, 因此, 响应因子也与区域 水资源安全指数呈正相关。

根据 DPSIR 模型中水资源安全各因子的 影响机制, 结合水资源安全评价的概念框架, 利用熵组合权重法, 建立如下水资源安全指数 模型:

$$
\text { WRSI }=\frac{\mathrm{S}^{\mathrm{WS}} \times \mathrm{R}^{\mathrm{WR}}}{\mathrm{D}^{\mathrm{WD}} \times \mathrm{P}^{\mathrm{WP}} \times \mathrm{I}^{\mathrm{WI}}}
$$

式中, WRSI (Water Resources Security Index) 是水资源安全指数, 用来表征水资源安全程度, 其值越大, 水资源安全的程度越高, 水资源越 安全; 其值越小, 表示该区域的水资源安全水 平越低, 水资源越不安全。 D、P、S、I、R 分 别表征驱动力、压力、状态、影响和响应 5 个 准则层因子指数。利用综合指数法, 分别求出 每个因子值, 见公式 $(2 、 3 、 4 、 5 、 6)$ :

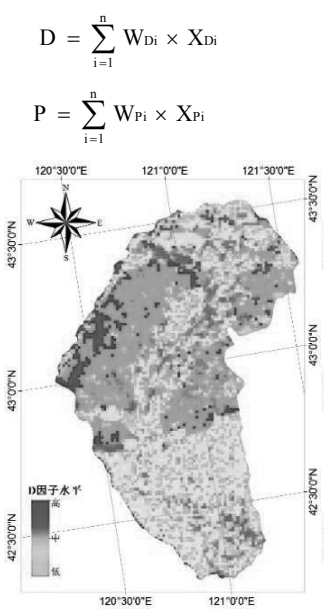

图 3. 驱动力因子水平

$$
\begin{aligned}
& \mathrm{S}=\sum_{\mathrm{i}=1}^{\mathrm{n}} \mathrm{W}_{\mathrm{Si}} \times \mathrm{X}_{\mathrm{Si}} \\
& \mathrm{I}=\sum_{\mathrm{i}=1}^{\mathrm{n}} \mathrm{W}_{\mathrm{Ii}} \times \mathrm{X}_{\mathrm{li}} \\
& \mathrm{R}=\sum_{\mathrm{i}=1}^{\mathrm{n}} \mathrm{W}_{\mathrm{Ri}} \times \mathrm{X}_{\mathrm{Ri}}
\end{aligned}
$$

式中, $\mathrm{n}$ 代表指标个数, $\mathrm{X}_{\mathrm{i}}$ 代表网格评价指标 $\mathrm{i}$ 标准化后的值, $\mathrm{W}_{\mathrm{i}}$ 代表评价指标 $\mathrm{i}$ 的权重, 用来表征各指标对水资源安全指数的相对重 要性。

\section{4. 结果分析}

\section{1. 准则层因子的空间特征}

为了从形成机制上讨论和分析奈曼旗水 资源安全空间分异特征的演进过程, 本研究利 用综合指数法得到了驱动力因子 (D)、压力因 子 $(P)$ 、状态因子 $(S)$ 、影响因子 $(I)$ 、响应 因子 (R) 的空间展布结果 (图 3 图 7)。

由图 3、图 4 可知, 奈曼旗压力因子的空 间分异受到其驱动力要素的直接影响。在西北 部沙沼稀疏草原区, 经济比较落后, 生产力水 平较低, 特别是近三十年来人口持续增加, 一 方面人们为满足不断增长的粮食需求将大面 积坨沼开脣为耕地; 另一方面, 当地牧民为增 加收入积极发展畜牧业, 使得当地草场放牧量 严重超载。在人口持续增加和追求畜牧业产值 增长双重因素的驱动下, 造成西北部沙沼稀疏 草原区压力因子水平极高。中北部区域 GDP

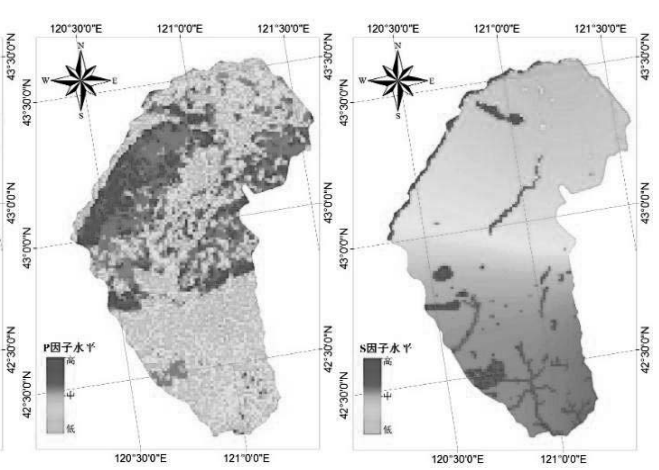

图 4. 压力因子水平

图 5. 状态因子水平 
Risk Analysis and Crisis Response in Big Data Era (RAC-16)

年平均增长率高达 $5 \%$, 人口增长速率为 $0.4 \% \sim 0.5 \%$, 远超过其 $0.11 \%$ 的平均增长水平, 进而引起道路网密度、人均水资源量、人均 GDP 等压力指标负向演变, 对水资源造成的压 力日益显现, 压力因子水平较高。在中南部低 山丘陵区以及西北部边缘平原区, 城镇化率高 达 $32 \%$, 高于其 $26 \%$ 的平均城镇化水平, 社会 经济水平较高, 道路网密度、人均 GDP、万 元 GDP 产值用水量等压力指标相对较大, 压 力因子水平相对较高。在北部湿地、林地以及 东南部低山丘陵区人类社会经济活动程度低, 路网密度小, 化肥、农药施用量低, 压力因子 水平极低。由图 5、图 6 可知, 奈曼旗状态因 子的空间分异主要受到气象要素和自身水域 景观分布的影响, 奈曼旗影响因子的空间分异 则受到了气象要素和土地利用格局的共同调 控。西北部沙沼稀疏草原区域以沙地为和稀疏 草原为主, 水环境自然状态值低, 生态结构不 稳定, 极易受到外界条件的影响, 影响力因子 水平极高, 而由图 7 可知, 当地对该区域的响 应值却很低, 几乎处于全旗最低水平, 相关部 门必须给予高度关注。

综上所述, 奈曼旗水资源安全状况具有空 间分异特征是驱动力、压力、状态、影响、响 应五因子相互影响、作用的结果。通过五因子 和水资源安全空间格局的对比分析, 我们发现 压力因子和响应因子水平对奈曼旗水资源安 全评价结果具有支配、导向地位。在压力大、 响应低地区, 尤其是西北部土地沙化区域, 有 关部门必须加强退耕还草、退耕还林工作, 严 格限制放牧数量, 加大对现有植被的保护力度, 从而实现水资源安全和区域经济和谐发展, 走 可持续发展道路。

\section{2. 水资源安全指数变化}

本文基于公里格网尺度, 以半干旱区奈曼 旗为例, 基于格网 GIS 共划分 8464 个研究小 区。根据公式 (1), 计算出这些研究小区的水 资源安全指数 (WRSI) 值。在考察当地水资 源安全实际状况, 并征询相关专家的基础上, 我们应用最佳自然间断点分级法对 WRSI 进 行等级划分, 将 WRSI 值与水资源安全水平关 联起来, 由低到高划分为: 不安全区 $(0.7669 \leq \mathrm{WRSI}<0.9770)$ 、欠安全区

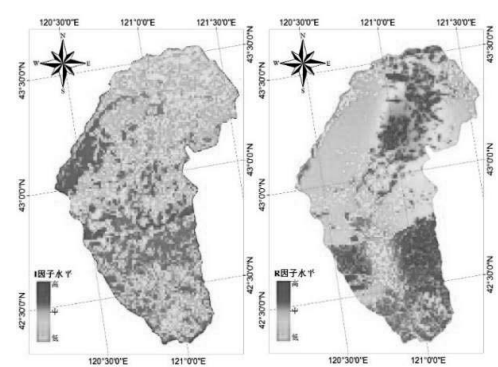

图 6 影响因子水平 图 7 响应因子水平

( $0.9770 \leq \mathrm{WRSI}<1.0681)$ 、较安全区 ( $1.0681 \leq \mathrm{WRSI}<1.1591)$ 和安全 区 (1.1591 $\leq \mathrm{WRSI}<1.3606)$ 等 4 个区间。利用 GIS 空间分析技术, 依据上述分级结果, 绘制 出奈曼旗水资源安全空间分布图（图 8)。

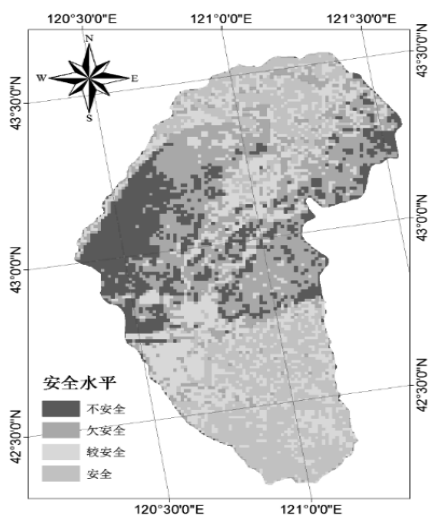

图 8 奈曼旗水资源安全空间差异分布

如图 8 所示, 研究区水资源安全状况具有 明显的空间分异特征。水资源安全状况最差的 区域面积为 $1424.0844 \mathrm{~km}^{2}$, 占全旗总面积的 $17.50 \%$, 主要分布在西北部沙沼稀疏草原区; 欠安全的区域面积为 $2438.9958 \mathrm{~km}^{2}$, 占全旗总 面积的 $29.97 \%$, 主要分布在奈曼旗中北部地 区; 水资源安全状况较好的地区面积为 $2285.6584 \mathrm{~km}^{2}$, 占全旗的 $28.09 \%$, 主要分布在 中南部低山丘陵区以及西北部边缘平原区; 水 资源安全状况最好的区域面积为 $1988.9614 \mathrm{~km}^{2}$, 占全区总面积的 $24.44 \%$, 主要 分布在北部湿地、林地以及南部低山丘陵区。 
Risk Analysis and Crisis Response in Big Data Era (RAC-16)

综上所述, 奈曼旗水资源安全状况不容乐观, 全旗近一半的区域水资源处于不安全或欠安 全水平, 仅 $24.44 \%$ 的区域水资源处于安全水 平, 相关部门必须高度重视水资源安全预警工 作, 以及有可能出现的旱灾问题, 尤其是在西 北部水资源安全状况较差的区域, 进而在最大 程度上减少当地居民的损失。

\section{5. 结论与讨论}

\section{1 . 结论}

（1）本文以奈曼旗为例，基于 DPSIR 模型 选取 19 个指标构建水资源综合评价模型, 利 用 WRSI 指数对其境内的水资源安全进行了综 合评价, 评价结果显示: 奈曼旗水资源安全状 况不容乐观, $17.50 \%$ 的地区水资源处于不安全 状态, 29.97\%的地区水资源处于欠安全状态。 (2) 本文研究结果与连杰、赵学勇等人 [12] 研究结果一致, 并且经过向当地相关部门咨询, 我们的水资源安全评价结果基本符合当地实 际情况, 为建立普遍适用的半干旱区水资源评 价体系提供了一定的参考思路, 对今后半干早 区制定经济发展和地区之间的水资源安全协 调政策提供了科学依据和方法支撑。

（3）奈曼旗地区水资源安全问题, 必然受半 干早区自然条件的约束, 但其水资源开发利用 程度不高、利用效率低等也是造成水资源紧缺 的重要原因。奈曼旗应在保证生态环境需水的 基础上, 通过提高水资源利用率、改善用水结 构、实施虚拟水战略等措施, 缓解当地水资源 蒉乏问题。

\section{2. 讨论}

由于地区经济发展水平和自然状况的差 异, 影响水资源安全的驱动力和压力因素在各 研究单元存在差别, 水资源安全的状态和响应 方式也不尽相同。本文基于 DPSIR 概念框架, 以空间分辨率 $1 \mathrm{~km} \times 1 \mathrm{~km}$ 的网格为研究单元, 打破了行政区研究尺度的限制, 进一步分析行 政单元内部水资源安全状况的地域差异，同时 其评价结果也便于向基于行政单元或流域单 元的水资源评价进行转化, 弥补了传统基于行 政区进行水资源安全的不足, 可为行政区内部 的微观水资源规划和管理提供参考和依据。

\section{Acknowledgements}

The study is financially supported by the National Nonprofit Research Program of China (No. 201401015).

\section{致谢}

本研究以水利部公益性行业科研专项经费项 目（201401015）为项目支撑.

\section{参考文献}

[1] 凌红波等, 基于 AHP 和模糊综合评判的玛 纳斯河流域水资源安全评价. 中国沙漠, 2010, 30(04): 989-994.

[2] Ding X, Wei W, Huang G, et al. A Two-Step Water-Management Approach for Nuclear Power Plants in Inland China. Journal of Risk Analysis and Crisis Response, 2014, 4(4) : 184-202.

[3] Habibi Davijani M, Banihabib M.E Nadjafzadeh Anvar, et al. Optimization model for the allocation of water resources based on the maximization of employment in the agriculture and industry sectors. Journal of Hydrology, 2016, 533: 430-438.

[4] 胡国华, 孙树青, 郭飞燕, 等. 黄河干 流水环境健康风险评价：中国灾害防御 协会风险分析专业委员会第二届年会, 中国四川成都, 2006.

[5] 俞博凡, 温丽丽, 宋永会, 等. 膜进样/ 飞行时间质谱在线监测水环境中挥发性 有机污染物及其在水源地污染事故监控 预警中的应用：中国灾害防御协会风险 分析专业委员会第四届年会, 中国吉林 长春, 2010 .

[6] 娄华君, 李涛, 王宏. 南水北调中线工程 的水量调蓄问题及对策: 中国灾害防御 协会风险分析专业委员会第四届年会, 中国北京, 2004 .

[7] 陈影, 任志远, 郭斌. 陕西省近 10 年来 水资源足迹动

[8] 任志远, 张艳芳. 土地利用变化与生态安 全评价. 北京: 科学出版社, 2006: 
Risk Analysis and Crisis Response in Big Data Era (RAC-16)

155-158.

[9] 张继权, 伊坤朋, Hiroshi Tani，等. 基 于 DPSIR 的吉林省白山市生态安全评价. 应用生态学报, 2011，22(01)：189-195.

[10] 陈华伟, 黄继文, 张欣, 等. 基于 DPSIR 概念框架的水生态安全动态评价. 人民 黄河, 2013, 35(09)：34-37.
[11] 曹琦, 陈兴鹏, 师满江. 基于 DPSIR 概念 的城市水资源安全评价及调控. 资源科 学, 2012, 34(08): 1591-1599.

[12] 连杰, 赵学勇, 左小安, 等. 科尔沉沙地水 域景观格局的时空动态-D以奈曼旗为 例. 中国沙漠, 2012, 32(01): 210-218. 